\title{
PIV MEASUREMENT OF CONSTANT AREA MIXING IN SUBSONIC AIR EJECTOR
}

\author{
Václav DVOŘÁK', Michal KOTEK ${ }^{*}$
}

\begin{abstract}
The article deals with experimental study of constant area mixing in subsonic axi-symmetric air ejector. The velocity fields inside the constant area mixing chamber were taken through the vitreous wall of the chamber, while the laser beam entered it from the opened outflow of the ejector. PIV measurements of four different mixing regimes, each with different ejection ratio were performed. Basic description of results are given and it is claimed that results are reliable. Obtained data will be later compared with constant temperature anemometry and with numerical calculations.
\end{abstract}

\section{INTRODUCTION}

The article deals with experimental investigation into the flow in a subsonic axisymmetric air ejector witch constant area mixing. Quite a number of researchers were concerned with ejectors and a great number of publications have been produced. For example, Sun and Eames [1] named over 100 citations in their overview from 1995. In a review carried out by Bonnington and King [2], 413 references dating prior 1976 were cited. Porter and Squyers [3] compiled a list of more than 1600 references relating to ejector theory and performances.

First methods of ejector design were based on experience. The first analysis of mixing was made by Keenan a Neumann [4]. They consider only the simplest form of ejector, a constant area mixing chamber without diffuser. They calculated the performance of an ejector using the one-dimensional continuity momentum and energy equations. Although the analysis was simplified, the results were consistent and compared well with experimental results. Later Keenan et al [5], in a follow up to their earlier work, considered mixing at constant pressure. This work produced the first comprehensive theoretical and experimental analysis of the ejector problem, and is the basis of much of what has taken place since. The constant pressure design method is used in the majority of ejector applications, and has caused the most problems for researchers. The main reason for this is the complex nature of the flow structure in the constant pressure mixing section. Also the determination of the mixing chamber geometry to ensure constant pressure mixing and best mixing is problematic. Only few authors were concerned with optimization of ejectors. Dvořák in work [6] optimized an ejector with the help of Fluent and verified a manufactured ejector experimentally.

\footnotetext{
- Doc. Ing. Václav Dvořák, Ph.D., Technical University of Liberec, Studentská 2, Liberec, Czech Republic, vaclav.dvorak@tul.cz

** Ing. Michal Kotek, Ph.D., Technical University of Liberec, Studentská 2, Liberec, Czech Republic, michal.kotek@tul.cz
}

This is an Open Access article distributed under the terms of the Creative Commons Attribution License 2.0, which permits unrestricted use, distribution, and reproduction in any medium, provided the original work is properly cited. 
The ejector was optimized by using turbulence model realizable $\mathrm{k}-\varepsilon$ with enhanced wall treatment. Model realizable $k-\varepsilon$ seemed to be the most suitable for axi-symmetric mixing problems according the results in work of Dvořák [7], also many researches use it, e.g. Rusly et al. [8], while e.g. Bartosiewicz at al. used turbulence model SST k- $\omega$ to simulate the flow in supersonic ejectors in work [9]. However, it was found out in work [6] that all numerical results for various turbulence models varied as compared with experiments. The aim of this study is to obtain complex experimental data with the help of PIV method. These data will be further compared with constant temperature anemometry and completed with pneumatic measuring for better determination of a suitable turbulence model describing properly the subsonic axi-symmetric mixing.

\section{Methods}

\section{Experimental setup}

A circular converging nozzle with diameter $d=19.2 \mathrm{~mm}$ was used as a primary nozzle. The mixing chamber had diameter $D=40 \mathrm{~mm}$. The area ratio of nozzles was $\mu=A_{1} / A_{2}=0.3$ and the relative length of the mixing chamber was $L / D=9$. A diffuser with $6^{\circ}$ enlargement and with outlet diameter $71.2 \mathrm{~mm}$ was placed behind the mixing chamber.

For slow pressure measuring, we used pressure sensors Druck LP 1000 with range 100, 500,1000 and $2000 \mathrm{~Pa}$. These low pressure sensors with high accuracy $0.25 \%$ are slow, so only mean value of pressures were measured. Arrangement of the experiments is obvious from Figure 1.

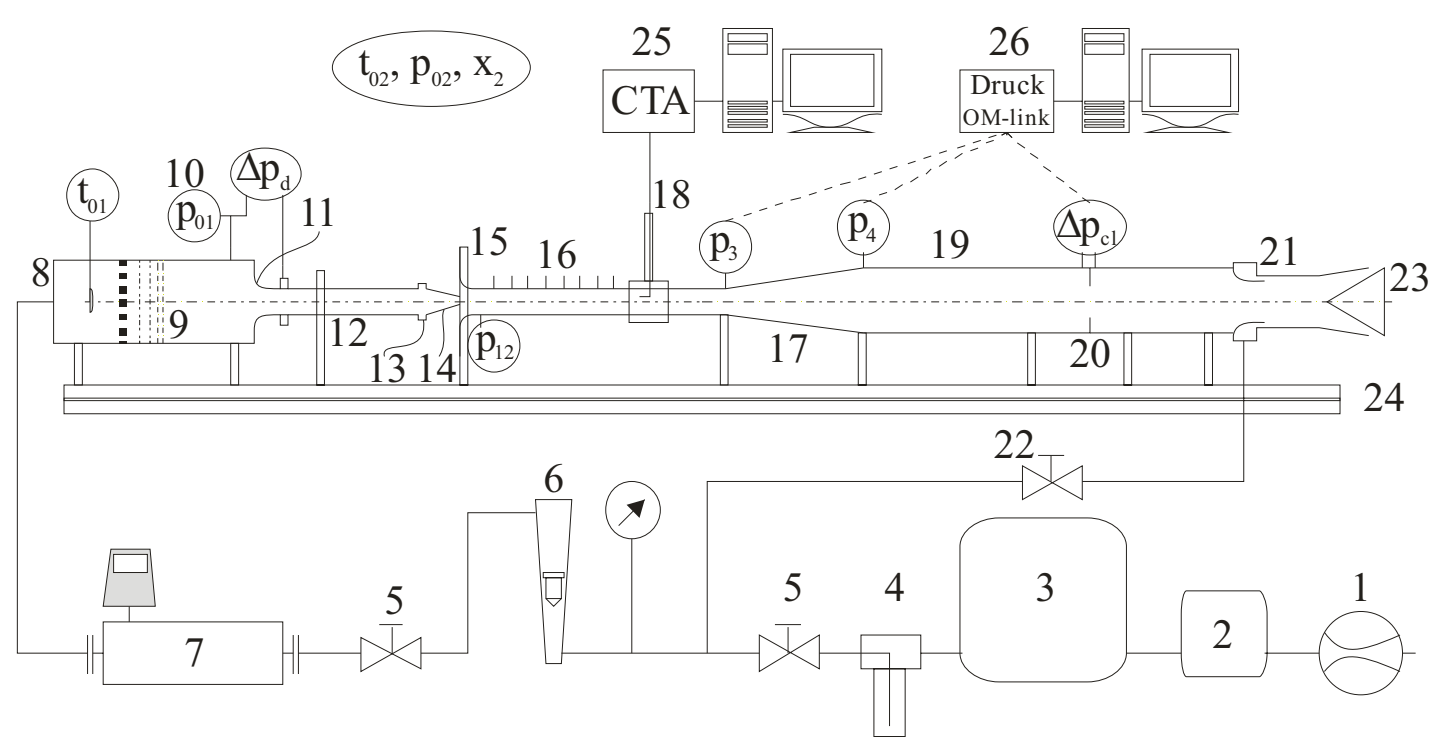

Figure 1: Experimental arrangement: 1 - compressor, 2 - air dryer, 3 - tank, 4 - filter, 5 - reduction valve, 6 - rotameter, 7 - Coriolis mass flow meter, 8 - stilling chamber, 9 - stilling riddles, 10 - measuring of primary stagnation pressure $p_{01}, 11$ - measuring of primary mass flow rate, 12 - primary flow supply tube, 13 - holder of primary nozzle, 14 - primary nozzle, 15 - secondary nozzle, 16 - mixing chamber with static pressure taps, 17 - diffuser, 18 - probes of constant temperature anemometry, 19 - outflow pipe, 20 - measuring of total mass flow rate, 21 - suction ejector, 22 - control valve, 23 - chocking, 24 - base, 25 - CTA measuring, 26 - pneumatic measuring. 
Experimental arrangement for investigation of mixing processes in ejectors is displayed in Figure 1. The primary air flowed from compressor through air dryer, control valves and stilling chamber, which guaranteed constant value of stagnation pressure. Measuring of primary mass flow rate was behind the stilling chamber. The secondary air was sucked in to the mixing chamber directly from the laboratory. A diffuser to obtain higher back pressure and a measuring orifice to measure total mass flow rate were placed behind the mixing chamber. Chocking placed in the end of tube was used for set-up of high back pressure and additional suction ejector was used for set-up of low or even negative back pressure. The over pressure of primary flow was $p_{01}-p_{02}=1000 \mathrm{~Pa}$, where $\mathrm{p}_{01}$ and $\mathrm{p}_{02}$ are stagnation pressures of primary and secondary flow.

\section{PIV Experimental setup}

Experimental study of flow field in ejector was realized with Particle Image Velocimetry system (PIV) from Dantec Dynamics. Investigated area was illuminated with New Wave Gemini double pulse laser. Images were captured with HiSense 12 bit camera. To reach sufficient spatial resolution, the flow field in mixing chamber was recorded sequentially in four steps. Figure 2 describes the arrangement of measuring PIV system and experimental setup.

The 1,3Mpixels camera covered the area of $80 \mathrm{~mm} \times 60 \mathrm{~mm}$ in each step. This setup led to approximately 30 points (velocity vectors) in velocity profile of mixing chamber (glass tube of $40 \mathrm{~mm}$ diameter). Self designed assembling algorithm was used to reconstruct the overall image of whole mixing chamber with length $320 \mathrm{~mm}$. This methodic had the same effect as a high sensitive PIV camera with an extreme spatial resolution of $5000 \mathrm{x}$ 1024 pixels.

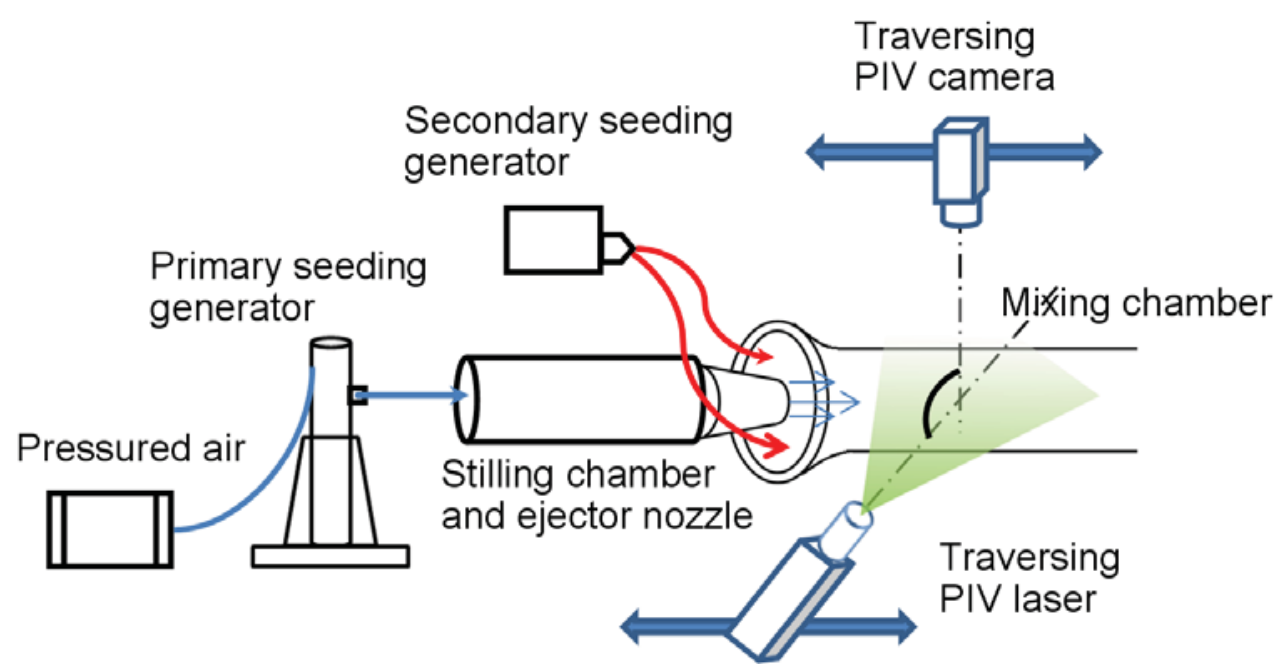

Figure 2: Sketch of PIV experimental arrangement.

As the PIV method calculates the velocity of tracking particles, the seeding of both air flows should be designed. The main primary pressured air was seeded with Sciltek oil droplets generator. Into the secondary flow, the seeding particles were brought with a system of pipes and a special seeding ring surrounded the main nozzle, just before the inlet to the mixing chamber. Secondary flow seeding particles were produced by Safex generator. Both particle types have same size distribution $(2-5 \mu \mathrm{m})$ and similar light scattering, so they can be combined in one PIV measurement. 
One hundred images were recorded for each step position and regime setup to ensure satisfactory data for statistical evaluation. Crosscorrelated PIV images were validated using Range and Moving average filter. Two statistical methods were used to calculate the mean velocity in each interrogation area. Mean value provides statistical information (standard deviation), but produces inaccurate values in the region of poor seeded flow. Better results of these poor seeded areas were obtained using Median. Extreme velocity values of some wrong correlated records do not influence the resultant value so dramatically.

\section{Results AND Discussion}

There are results of PIV measurements in Figures 3, 4, 5 and 6, both velocity contours and velocity vectors. These figures represent velocity fields for four different regimes of ejector, which are specified in Figure 7. The first regime in Figure 3 is defined by zero back pressure $\mathrm{p}_{4}$, this pressure was measured behind the ejector diffuser. As a result, the ejection ratio, i.e. the ratio of mass flow rates $\Gamma=m_{2} / m_{1}=1.9$ was obtained. The second regime in Figure 4 was obtained for positive back pressure with $\Gamma=1.4$. The third regime was defined by zero mixing pressure $p_{3}$, which is measured behind the mixing chamber. For this case, the ejection ration was $\Gamma=1.1$. The fourth regime for the highest back pressure was of $\Gamma=0.5$. It is obvious from both velocity contours and vectors that the velocity fields decelerated for higher back pressure and lower ejection ratio, see Figure 7a. Likewise, we can also observe slower velocities of the secondary flow near the mixing chamber wall, lower velocity at the end of the mixing chamber and faster mixing.

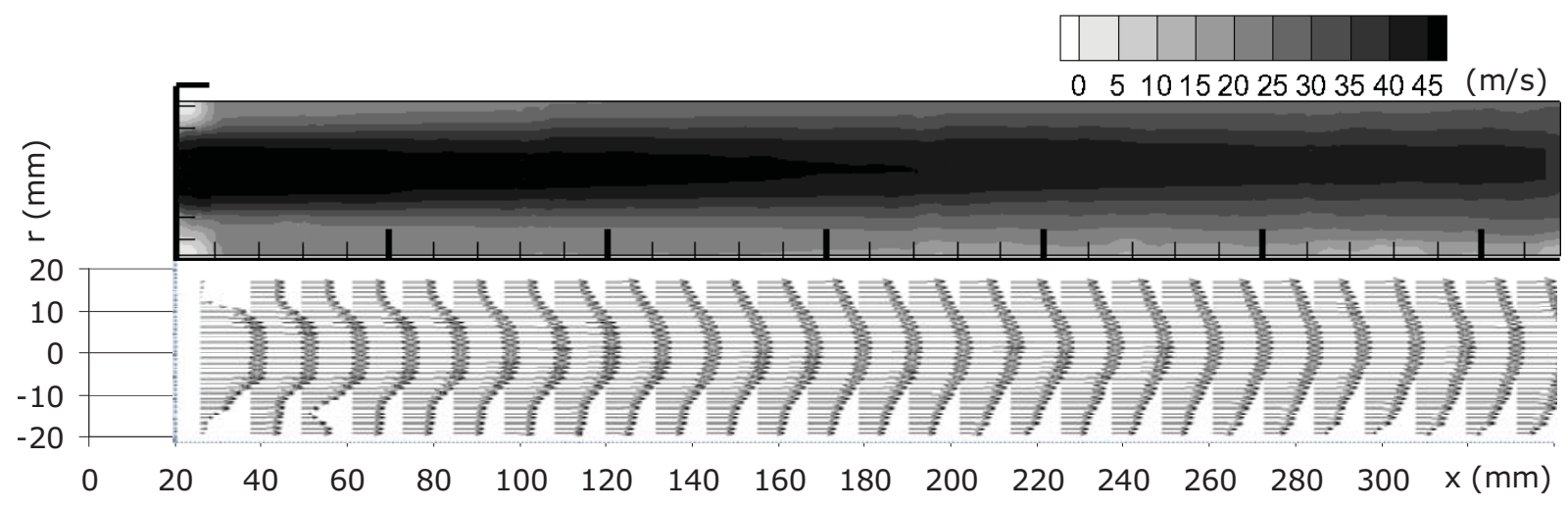

Figure 3: Velocity contours and vectors for regime 1, $\Gamma=1.9$.

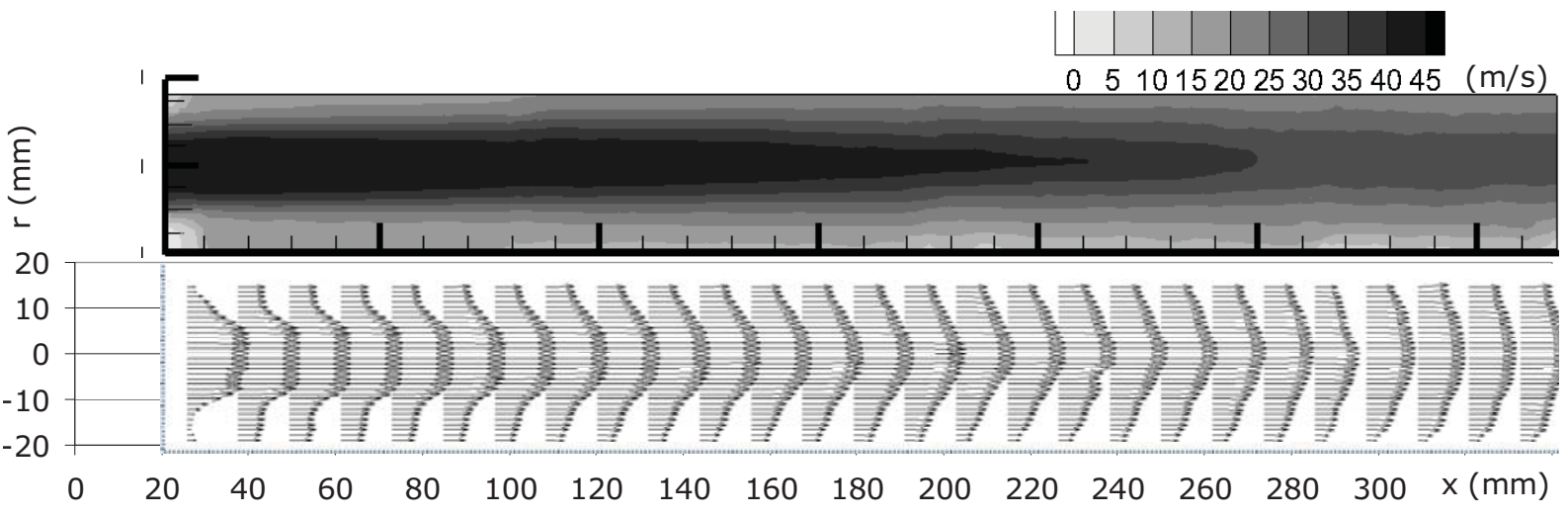

Figure 4: Velocity contours and vectors for regime $2, \Gamma=1.4$. 


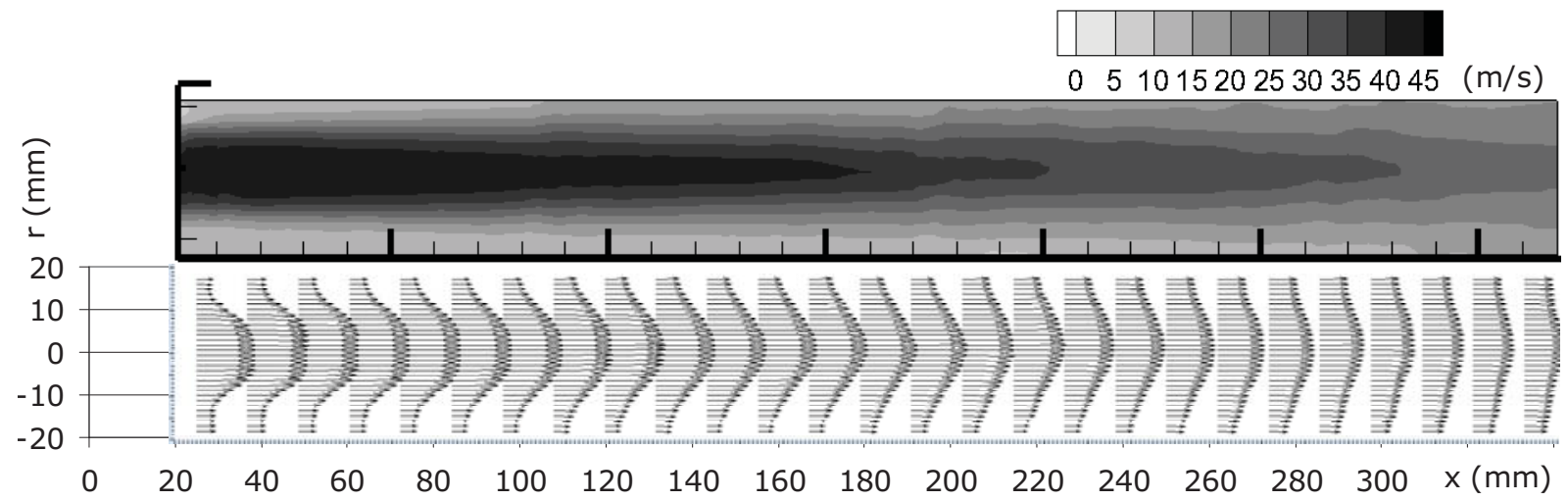

Figure 5: Velocity contours and vectors for regime $3, \Gamma=1.1$.

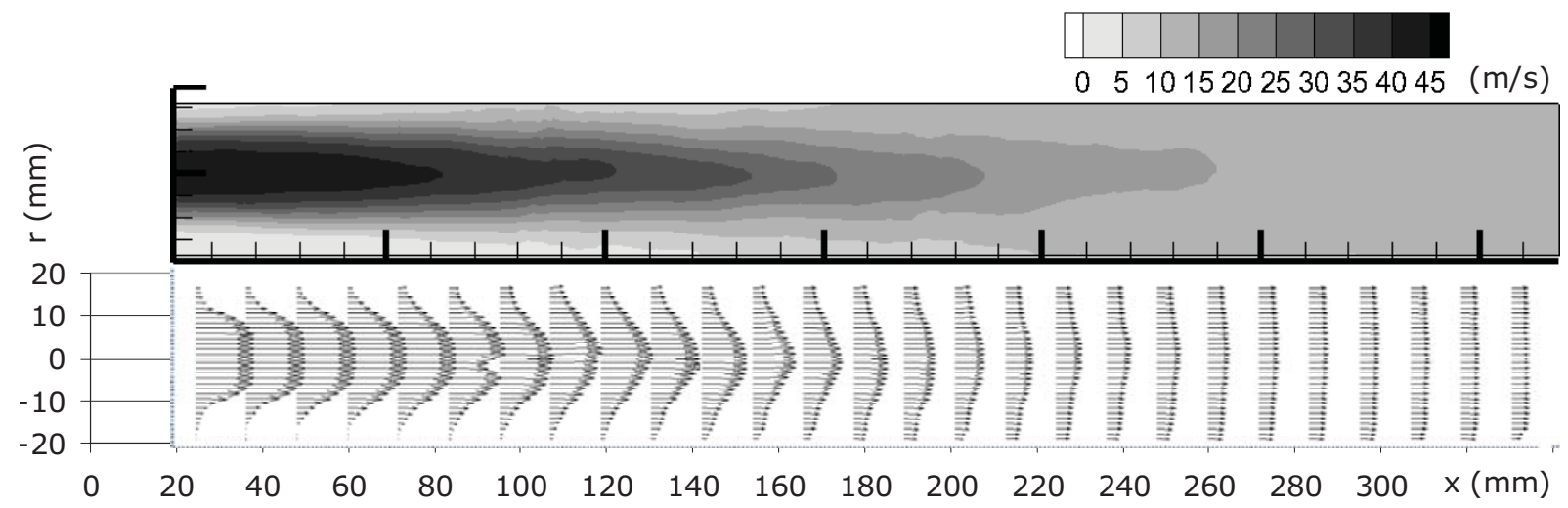

Figure 6: Velocity contours and vectors for regime $4, \Gamma=0.5$.

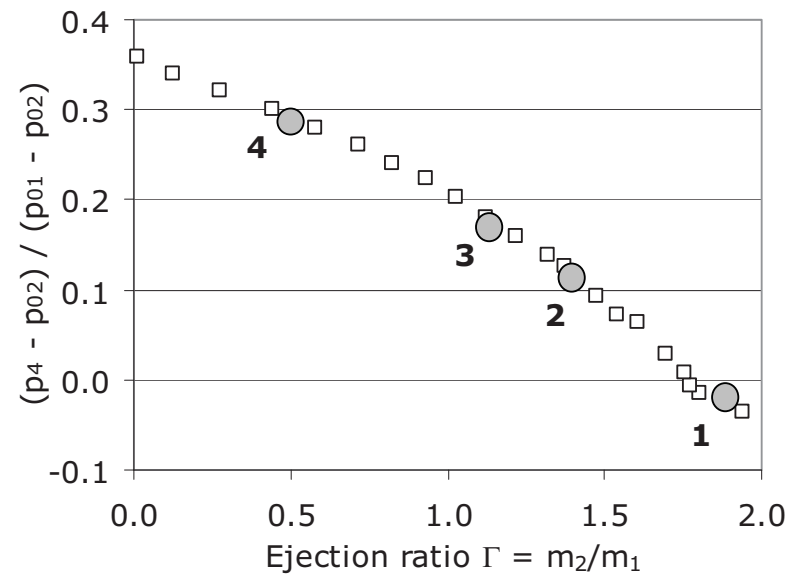

a) Relative back pressure.

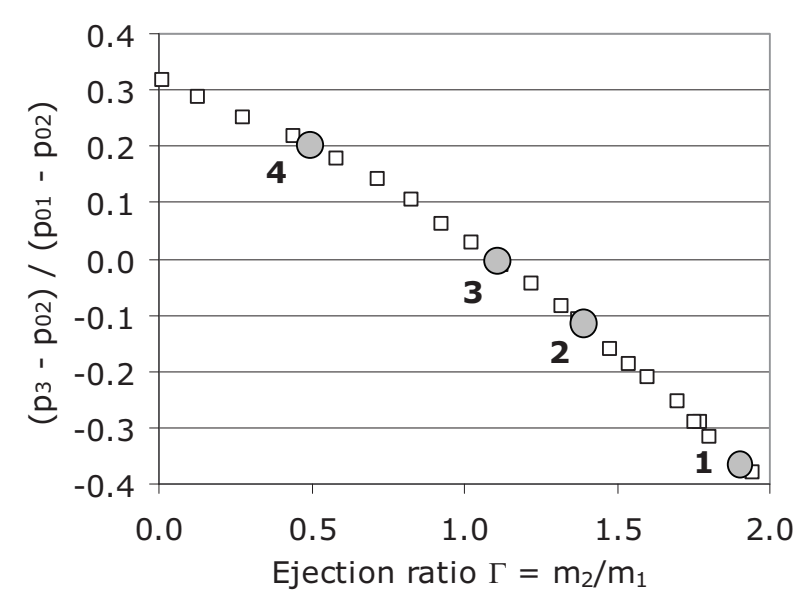

b) Relative mixing pressure.

Figure 7: Specifications of measured ejector regimes.

Figures 3, 4, 5 and 6 illustrate the mixing processes clearly, although there are evident some strange and likely false results, e.g. the third velocity profile in Figure 3, or the first in Figure 4 and the sixth in Figure 6. Generally, the obtained velocity profiles are smoother for higher back pressure (see regimes 3 and 4) than for low, see regimes 1 and 2. This is caused by low-frequency oscillations of flow field due to slow mixing. Fluctuations increase with higher ejection ratio. For smoother profiles, more images should be captured and evaluated, but these defects will never vanish. 


\section{Conclusion}

Particle image velocimetry was used to acquire velocity field in axi-symmetric subsonic air ejector with constant area mixing chamber. Four regimes with various ejection ratios were measured and velocity profiles and contours were obtained. The development of velocity profile in the mixing chamber is well observable from data. Despite to some imperfections, the results are applicable for further work, i.e. for comparison with constant temperature anemometry and numerical calculations using various turbulence models. Data can be also confronted with pneumatic measuring of static pressure distribution on the mixing chamber wall and regions of mixing can be determined.

\section{ACKNOWLEDgemENT}

This project was realized with financial support by the Czech Science Foundation, grant no. P101/10/1709.

\section{REFERENCES}

[1] Sun D.W., Eames I.W.: Recent Developments in the Design Theories and Applications of Ejectors - a review. Journal of the Institute of Energy, 1995, pp $65-79$.

[2] Bonnington S.T., King A.L.: Jet Pumps and Ejectors, a State of the Art; Review and bibliography (2nd edn). BHRA Fluid Eng, Cranfield, Bedford UK, 1976.

[3] Porter J.L., Squyers R.A.: A Summary/Overview of Ejector Augmentor Theory and Performance. ATC Report No. R-91100/9CR-47A, Vought Corpn Advanced Technology $\mathrm{Cr}$, Dallas, Texas, 1981.

[4] Keenan J.H., Neumann E.P.: A Simple Air Ejector. J Applied Mechanics, Trans ASME, 1942, 64, pp A75 - A81.

[5] Keenan J.H., Neumann E.P., Lustwerk F.: An Investigation of Ejector Design by Analysis and Experiment. J Applied Mechanics, Trans ASME, 1950, 72, pp 299309.

[6] Dvořák V.: Optimized Axi-Symmetric Ejector - Experimental and Numerical Investigation. In: Experimental Fluid Mechanics 2009, Liberec 25. - 27. November 2009, pp $34-43$.

[7] Dvořák V.: Numerical Computation of Efficiency Curve of Ejector. Konference ANSYS 2007, FLORET, Prague, 2007, pp 149 - 156.

[8] Rusly E., Lu Aye, Charters W.W.S., Ooi A.: CFD analysis of ejector in a combined ejector cooling system. International Journal of Refrigeration 28 (2005), pp 1092 - 1101.

[9] Bartosiewicz Y., Aidoun Z., Desevaux P., Mercadier Y.: Numerical and experimental investigations on supersonic ejectors. International Journal of Heat and Fluid Flow 26 (2005), pp 56 - 70. 